\title{
Efektifitas Penyuluhan Kesehatan Sadari Dengan Media Video Terhadap Pengetahuan Pada Remaja Putri Di Smk Muhammadiyah Cawas Klaten
}

\section{Effectiveness Of Sadari Health Education Using Video On Adolescent Girls Knowledge In Muhammadiyah Cawas Klaten Vocational High School}

\author{
Novaria Wijayanti ${ }^{1}$, Triyanta ${ }^{2}$, Nur $\mathrm{Ani}^{3}$ \\ Program Studi Kesehatan Masyarakat Universitas Veteran Bangun Nusantara \\ Email: novariawijaya@gmail.com
}

\begin{abstract}
The incidence of breast cancer from year to year is increasing. This was partly due to the low knowledge of young women about SADARI so that $70 \%$ of them come in advanced stages (III and IV) and $80 \%$ of people do not understand the importance of SADARI. Therefore, BSE needs to be understood and known by young women so that it can be applied routinely to detect breast health problems early. This research purpose to find out the effectiveness of SADARI health education with video on Adolescent Girls Knowledge in Muhammadiyah Cawas Klaten Vocational High School.

This research was a quantitative study using a pre experimental design. The study was conducted starting in August 2019 with a sample of 69 students taken by total sampling. The independent variable was SADARI health education with video media and the dependent variable was knowledge about SADARI. The research instrument used a questionnaire. The data analysis technique used Wilcoxon signed rank test.

The results of the study were known before the health education using video the majority of young women knowledge including enough as much as $47,8 \%$ and after the health education using video the majority of young women knowledge including good as much as 58\%. Hypothesis test results indicate that the significance of $0,000<0.05$ so that there were differences in knowledge of addolescent girls before and after health education about SADARI through video.

The conclusion of this research was giving health education about SADARI through video effectively increases the knowledge of addolescent girls. Based on the result, it was suggested for Muhammadiyah Cawas Klaten Vocational High School should be to using video as teaching materials related to breast health and early detection of breast cancer to increase the knowledge of children of productive age.
\end{abstract}

Keywords: SADARI examination, knowledge, video

\begin{abstract}
ABSTRAK
Angka kejadian kanker payudara dari tahun ke tahun semakin meningkat. Hal ini salah satunya dikarenakan masih rendahnya pengetahuan remaja putri mengenai SADARI sehingga $70 \%$ banyak yang datang dalam keadaan stadium lanjut (III dan IV) dan $80 \%$ masyarakat tidak mengerti pentingnya SADARI. Oleh karena itu, SADARI perlu dipahami dan diketahui oleh remaja putri sehingga dapat diterapkan secara rutin untuk mendeteksi dini masalah kesehatan payudara. Tujuan dari penelitian ini untuk mengetahui efektifitas penyuluhan kesehatan SADARI dengan media video terhadap pengetahuan remaja putri di SMK Muhamamdiyah Cawas Klaten.
\end{abstract}


Penelitian ini merupakan penelitian kuantitatif menggunakan desain Pre Experimental Design. Penelitian dilaksanakan mulai bulan Agustus 2019 dengan sampel sebanyak 69 siswi yang diambil secara total sampling. Variabel bebas adalah penyuluhan kesehatan SADARI dengan media video dan variabel terikat adalah pengetahuan tentang SADARI. Instrumen penelitian menggunakan kuesioner. Teknik analisis data menggunakan wilcoxon signed rank test.

Hasil penelitian diketahui sebelum penyuluhan kesehatan dengan media video pengetahuan remaja putri mayoritas cukup sebanyak $47,8 \%$ dan sesudah diberikan penyuluhan kesehatan dengan media video pengetahuan remaja putri mayoritas baik sebanyak 58\%. Hasil uji hipotesis menunjukkan bahwa signifikansi $0,000<0,05$ sehingga terdapat perbedaan pengetahuan remaja putri sebelum dan sesudah penyuluhan kesehatan tentang SADARI melalui media video.

Kesimpulan penelitian ini adalah pemberian penyuluhan kesehatan tentang SADARI melalui media video efektif meningkatkan pengetahuan remaja putri. Saran untuk SMK Muhammadiyah Cawas Klaten hendaknya dapat menggunakan media video sebagai bahan ajar terkait kesehatan payudara dan deteksi dini kanker payudara untuk meningkatkan pengetahuan anak usia produktif.

Kata kunci: pemeriksaan SADARI, pengetahuan, media video

\section{PENDAHULUAN}

Penyakit kanker merupakan salah satu penyebab kematian utama diseluruh dunia. Salah satu penyakit kanker yang banyak terjadi pada wanita adalah kanker payudara yaitu tumor ganas yang tumbuh didalam jaringan payudara yang meliputi kelenjar susu, saluran susu, jaringan lemak, maupun jaringan ikat pada payudara (Lubis, 2017). Kanker payudara adalah tumor ganas pada payudara atau salah satu payudara, kanker payudara juga merupakan benjolan atau massa tunggal yang sering terdapat di daerah kuadrat atas bagian luar, benjolan ini keras dan bentuknya tidak beraturan dan dapat digerakkan (Olfah, 2013).

Kanker payudara merupakan penyakit kanker dengan persentase kasus baru yang tertinggi. Jumlah penderita kanker payudara meningkat sebesar 1,7 juta perempuan dari sebelumnya 6,3 juta yang terdiagnosa hidup dengan kanker payudara pada 5 tahun terakhir. Kanker payudara juga merupakan kanker yang menjadi penyebab paling umum kematian kaum perempuan yaitu sebesar 522.000 kematian (WHO, 2013).

Kanker payudara dapat dideteksi lebih dini dengan cara pemeriksaan payudara sendiri untuk mengetahui stadium awal, sehingga pengobatan dini akan memperpanjang hidup penderita kanker payudara. Pemeriksaan payudara sendiri (SADARI) bisa diterapkan pada remaja putri yang mengalami perubahan fisik dan perkembangan seks sekunder yaitu masa pubertas mengalami pembesaran payudara terjadi pada usia 12-13 tahun (Manuaba, Manuaba, \& Fajar, 2015).

SADARI yaitu pemeriksaan yang mudah dilakukan oleh setiap wanita untuk mengetahui adanya benjolan atau kelainan payudara lainnya. Tujuan utama SADARI adalah menemukan kanker dalam stadium dini sehingga pengobatannya menjadi lebih baik, sayangnya wanita melakukan SADARI masih sangat rendah (Siburian, 2015). Masih minimnya wanita Indonesia khususnya remaja dalam melakukan SADARI dilatar belakangi oleh masih banyak remaja Indonesia belum peka terhadap perawatan payudaranya sendiri, mereka lebih peka terhadap jerawat yang timbul diwajah daripada adanya gejala kanker payudara, dan juga dilatar belakangi oleh kurangnya informasi dan kemauan untuk menggali informasi mengenai pencegahan kanker payudara. Selain itu, teknik SADARI masih awam, karena masih sedikit jumlah wanita yang rutin melakukan SADARI (Henny, 2012). 
Salah satu upaya dalam memperkenalkan serta meningkatkan pengetahuan masyarakat mengenai kesehatan adalah melalui penyuluhan kesehatan. Salah satu alat bantu atau media yang digunakan untuk menyampaikan pesan penyuluhan kesehatan guna menuju tercapainya tujuan penyuluhan adalah media audio visual. Media audio visual merupakan jenis media yang selain mengandung unsur suara juga mengandung unsur gambaran yang dapat dilihat, seperti rekaman video, slide suara dan lain sebagainya. Kemampuan media audio visual ini dianggap lebih baik dan menarik, sebab mengandung kedua unsur, yaitu didengar dan dilihat (Notoatmodjo, 2015).

Berdasarkan data dari WHO pada Februari 2019 menerangkan bahwa Data Global Cancer Observatory 2018 dari World Health Organization (WHO) menunjukkan kasus kanker yang paling banyak terjadi di Indonesia adalah kanker payudara, yakni 58.256 kasus atau 16,7\% dari total 348.809 kasus kanker. Kanker serviks (leher rahim) merupakan jenis kanker kedua yang paling banyak terjadi di Indonesia sebanyak 32.469 kasus atau 9,3\% dari total kasus. Kementerian Kesehatan (Kemenkes) menyatakan, angka kanker payudara di Indonesia mencapai 42,1 orang per 100 ribu penduduk. Rata-rata kematian akibat kanker ini mencapai 17 orang per 100 ribu penduduk. Sementara itu, angka kanker serviks di Indonesia mencapai 23,4 orang per 100 ribu penduduk. Rata-rata kematian akibat kanker serviks mencapai 13,9 orang per 100 ribu penduduk. Upaya pencegahan dan pengendalian kedua jenis kanker tersebut dilakukan dengan cara deteksi dini pada perempuan usia 30-50 tahun. Metode yang digunakan adalah Pemeriksaan Payudara Klinis (SADANIS) dan inspeksi visual dengan asam asetat (IVA) untuk kanker serviks (WHO, 2018).

Profil Kesehatan Provinsi Jawa Tengah Tahun 2018, kasus penyakit kanker yang ditemukan di Provinsi Jawa Tengah mulai tahun 2012 sampai tahun 2018 selalu mengalami peningkatan kejadian kanker. Tahun 2018 sebanyak 9.145 kasus, lebih sedikit di banding tahun 2012 (11.341 kasus). Pada perempuan mengalami kanker payudara dan kanker serviks sedangkan pada laki-laki mengalami kanker paru-paru. Penyakit kanker payudara terdiri dari 4.761 kasus (52,06\%). Dari data tersebut kejadian kanker payudara di wilayah Jawa Tengah Kabupaten Klaten memiliki 832 kasus. Dinkes Jateng juga telah melakukan upaya pengendalian penyakit tidak menular tersebut. Diantaranya melalui program-program yang tidak hanya bersifat mengobati, tetapi juga pencegahan penyakit melalui pola hidup sehat. Program tersebut di antaranya adalah Sadari dan Sadanis. Program sadari, yang dilakukan masyarakat sendiri dan program oleh tenaga Kesehatan, namanya Sadanis (Pemeriksaan Payudara oleh Tenaga Medis) (Dinkes Propinsi Jawa Tengah, 2018).

Berdasarkan uraian tersebut tujuan penelitian ini adalah untuk mengetahui efektifitas penyuluhan kesehatan SADARI dengan media video terhadap pengetahuan remaja putri di SMK Muhammadiyah Cawas Klaten.

\section{METODE}

Penelitian ini menggunakan metode Pre Experimental dengan one group pre-test post-test design. Adapun desain penelitian digambarkan sebagai berikut:

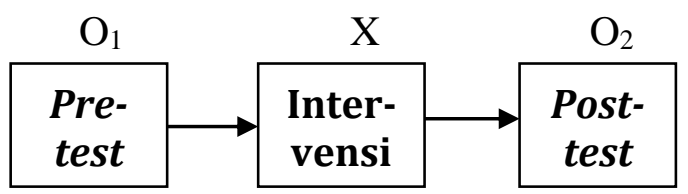

Gambar 1. Desain Penelitian 
Keterangan:

$\mathrm{O}_{1}$ : Mengukur gambaran remaja putri SMK Muhammadiyah Cawas mengenai SADARI sebelum diberikan pendidikan kesehatan dengan media video

$\mathrm{X}$ : Memberikan intervensi berupa pendidikan kesehatan dengan media video SADARI kepada responden $\mathrm{O}_{1}$

$\mathrm{O}_{2}$ : Mengukur kembali gambaran pengetahuan remaja putri SMK Muhammadiyah Cawas mengenai SADARI setelah diberikan pendidikan kesehatan dengan media video.

Penelitian dilaksanakan mulai bulan Agustus 2019 sampai selesai di SMK Muhammadiyah Cawas Klaten. Sampel dalam penelitian ini adalah seluruh siswi di SMK Muhammadiyah Cawas kelas 2 sebanyak 69 siswi diambil secara total sampling.

Pengetahuan tentang SADARI adalah segala sesuatu yang diketahui oleh remaja putri tentang SADARI yang meliputi pengertian, manfaat, langkah-langkah, tanda yang harus diwaspadai. Pengukuran pengetahuan dengan menggunakan kuesioner dengan skala guttman dan terdiri dari 15 item pertanyaan. Hasil ukur pengetahuan dikategorikan menjadi 3 yaitu:

a. Baik : jika nilai $12-15$

b. Cukup : jika nilai 9-11

c. Kurang : jika nilai 0-8

Teknik analisis data menggunakan analisis univariat untuk menjelaskan atau mendeskripsikan karateristik setiap variabel penelitian. Penyajian data univariat berupa distribusi frekuensi dan prosentase dari masing-masing variabel penelitian. Analisis bivariat menggunakan analisis data statistik Wilcoxon Rank Test dikarenakan hasil uji normalitas diperoleh sebaran data tidak normal $(\mathrm{p}<0,05)$.

\section{Analisis Univariat}

Berdasarkan hasil penelitian, diperoleh data distribusi responden berdasarkan karakteristik responden seperti disajikan pada Tabel 1. 
Tabel 1. Distribusi Responden Berdasarkan Karakteristik

\begin{tabular}{|c|c|c|}
\hline Karakteristik Responden & $\begin{array}{l}\text { Frekuensi } \\
(\mathrm{n}=69)\end{array}$ & $\begin{array}{l}\text { Prosentase } \\
(100 \%)\end{array}$ \\
\hline \multicolumn{3}{|l|}{ Umur } \\
\hline 16 tahun & 23 & $33,3 \%$ \\
\hline 17 tahun & 46 & $66,7 \%$ \\
\hline Pernah Mendapatkan & & \\
\hline \multicolumn{3}{|l|}{ SADARI } \\
\hline Belum & 61 & $88,4 \%$ \\
\hline Pernah & 8 & $11,6 \%$ \\
\hline \multicolumn{3}{|c|}{$\begin{array}{l}\text { Waktu mendapatkan Penyuluhan } \\
\text { SADARI }\end{array}$} \\
\hline 1 bulan lalu & 3 & $4,3 \%$ \\
\hline 3 bulan lalu & 2 & $2,9 \%$ \\
\hline 6 bulan lalu & 1 & $1,4 \%$ \\
\hline 1 tahun lalu & 2 & $2,9 \%$ \\
\hline $\begin{array}{l}\text { Mendapat Penyuluhan } \\
\text { dari ... }\end{array}$ & & \\
\hline Petugas Kesehatan & 5 & $7,2 \%$ \\
\hline Media Massa & 1 & $1,4 \%$ \\
\hline Leaflet & 2 & $2,9 \%$ \\
\hline
\end{tabular}

Sumber: Data primer diolah, 2019

Berdasarkan tabel 1 distribusi karakteristik responden diatas dapat diketahui bahwa mayoritas siswi kelas XI berumur 17 tahun sebanyak 46 orang $(66,7 \%)$ dan yang berusia 16 tahun sebanyak 23 orang $(33,3 \%)$. Dilihat dari pernah atau belum memperoleh penyuluhan kesehatan tentang SADARI ternyata mayoritas belum pernah memperoleh yaitu sebanyak 61 orang $(88,4 \%)$ dan hanya 8 orang siswi $(11,6 \%)$ yang pernah mendapatkan penyuluhan kesehatan tentang SADARI. Dari 8 orang siswi yang pernah memperoleh penyuluhan kesehatan tentang SADARI mayoritas mereka mendapatkan 1 bulan lalu sebanyak 3 orang $(4,3 \%)$ sedangkan mereka mendapat penyuluhan kesehatan tentang SADARI mayoritas mereka peroleh dari petugas kesehatan yaitu sebanyak 5 orang $(7,2 \%)$.

Hasil analisa univariat pengetahuan remaja putri sebelum dan sesudah diberikan penyuluhan kesehatan tentang SADARI dengan media video dilihat dari statistik deskriptif disajikan pada Tabel 2 berikut ini.

Tabel 2. Distribusi Pengetahuan Remaja Putri Sebelum dan Sesudah Diberikan Penyuluhan Kesehatan Tentang SADARI dengan Media Video dilihat dari Statistik Deskriptif

\begin{tabular}{lrllll}
\hline $\begin{array}{l}\text { Pengetahuan Remaja } \\
\text { Tentang SADARI }\end{array}$ & Putri N & Mean & $\begin{array}{l}\text { Std. } \\
\text { Deviation }\end{array}$ & Minimum Maximum \\
\hline Sebelum & 69 & 9,39 & 2,197 & 4,00 & 12,00 \\
Sesudah & 69 & 11,61 & 1,895 & 8,00 & 14,00 \\
\hline
\end{tabular}

Sumber: Data primer diolah, 2019 
Berdasarkan hasil statistik deskriptif seperti pada tabel 2 pengetahuan remaja putri antara sebelum dan sesudah diberikan penyuluhan kesehatan tentang SADARI dengan media video diketahui bahwa diperoleh nilai rata-rata pengetahuan sebelum diberikan penyuluhan kesehatan dengan media video sebesar 9,39 dan nilai rata-rata pengetahuan sesudah diberikan penyuluhan kesehatan dengan media video adalah 11,61. Hal ini dapat diartikan bahwa terdapat peningkatan pengetahuan remaja putri tentang SADARI setelah diberikan penyuluhan kesehatan dengan media video.

Hasil analisa univariat pengetahuan remaja putri sebelum dan sesudah diberikan penyuluhan kesehatan tentang SADARI dengan media video dilihat dari pengkategorian tingkat pengetahuan disajikan pada Tabel 3 berikut ini.

Tabel 3. Distribusi Pengetahuan Remaja Putri Sebelum dan Sesudah Diberikan Penyuluhan Kesehatan Tentang SADARI dengan Media Video dilihat dari Kategori

\begin{tabular}{lcccc}
\hline \multirow{2}{*}{\begin{tabular}{c} 
Pengetahuan Remaja Putri Tentang \\
\cline { 2 - 5 }
\end{tabular}} & \multicolumn{2}{c}{ Sebelum } & \multicolumn{2}{c}{ Sesudah } \\
\cline { 2 - 5 } & $\mathbf{n}$ & $\mathbf{\%}$ & $\mathbf{n}$ & $\boldsymbol{\%}$ \\
\hline Kurang & 20 & $29,0 \%$ & 5 & $7,2 \%$ \\
Cukup & 33 & $47,8 \%$ & 24 & $34,8 \%$ \\
Baik & 16 & $23,2 \%$ & 40 & $58,0 \%$ \\
\hline Total & 69 & $100 \%$ & 69 & $100 \%$ \\
\hline
\end{tabular}

Sumber: Data primer diolah, 2019

Berdasarkan hasil analisis univariat seperti yang disajikan pada tabel 3 diketahui bahwa sebelum dilakuka penyuluhan kesehatan tentang SADARI tingkat pengetahuan remaja putri di SMK Muhammadiyah Cawas Klaten mayoritas termasuk cukup sebanyak 33 orang (47,8\%), namun setelah dilakukan penyuluhan kesehatan tentang SADARI pengetahuan siswi meningkat dengan mayoritas siswi mempunyai pengetahuan baik sebanyak 40 orang $(58 \%)$.

\section{Analisis Bivariat}

Hasil pengujian hipotesis menggunakan Wilcoxon Signed Rank Test disajikan pada tabel 4 sebagai berikut.

Tabel 8. Distribusi Perbedaan Pengetahuan Remaja Putri Sebelum dan Sesudah diberikan Penyuluhan Kesehatan tentang SADARI Melalui Media Video

\begin{tabular}{lllll}
\hline Pengetahuan & N & Mean & Z score & Sig. \\
\hline Sebelum & 69 & 9,39 & 6,798 & 0,000 \\
Sesudah & 69 & 11,61 & & \\
\hline
\end{tabular}

Sumber: Data primer diolah, 2019

Hasil pengujian hipotesis menggunakan uji wilcoxon signed rank test diperoleh nilai $z$ score sebesar 6,798 dengan signifikansi sebesar $0,000<0,05$. Hal ini dapat diartikan bahwa terdapat perbedaan pengetahuan remaja putri antara sebelum dan sesudah diberikan penyuluhan kesehatan tentang SADARI melalui media video, dengan nilai rata-rata (mean) pengetahuan sebelum diberikan penyuluhan kesehatan sebesar 9,39 dan sesudah diberikan penyuluhan kesehatan tentang SADARI melalui media video pengetahuan remaja putri mengalami peningkatan dengan nilai rata-rata sebesar 11,61. Sehingga Ho ditolak dan Ha diterima artinya pemberian penyuluhan kesehatan tentang SADARI melalui media video efektif meningkatkan pengetahuan remaja putri di SMK Muhammadiyah Cawas Klaten 


\section{PEMBAHASAN \\ Pengetahuan Remaja Putri Sebelum Diberikan Penyuluhan Kesehatan melalui Media Video tentang SADARI}

Berdasarkan deskripsi data penelitian didapatkan hasil rata-rata (mean) skor pretest sebesar 9,39 dari 15 item pertanyaan yang diajukan. Sedangkan dilihat dari pengkategorian diketahui mayoritas siswi di SMK Muhammadiyah Cawas Klaten mempunyai pengetahuan cukup sebanyak 47,8\% dan pengetahuan siswi yang kurang juga masih cukup banyak yaitu sebanyak 29\% dibandingkan siswi yang berpengetahuan baik hanya sebesar 23,2\%.

Menurut asumsi peneliti masih kurangnya pengetahuan siswi terkait prosedur pemeriksaan SADARI yang dapat mencegah terjadinya kanker payudara dapat disebabkan masih rendahnya pengalaman siswi terkait hal tersebut. Selain itu siswi malas untuk menggali informasi yang sebenarnya banyak tersebar di media massa, leaflet atau media komunikasi yang lainnya, karena kurangnya terpapar informasi tentang pemeriksaan SADARI baik melalui media video, leaflet, televisi maupun penyuluhan kesehatan lainnya. Remaja putri lebih memiliki kecenderungan menyukai hal-hal yang bersifat pertemanan, fashion, percintaan dan lain sebagainya dibandingkan masalah kesehatan terutama personal care. Oleh karena itu, para remaja putri tersebut kurang atau tidak memiliki pengalaman untuk melakukan pemeriksaan SADARI. Ketika seseorang tidak memiliki pengalaman dan informasi yang kurang maka seseorang dapat berperilaku berbahaya bagi dirinya sendiri. selain itu faktor lingkungan sekolah yang kurang memberikan informasi tentang SADARI, sehingga informasi tersebut sangat dibutuhkan untuk meningkatkan pengetahuan siswi. Kurang terpaparnya informasi tentang SADARI baik melalui video, televisi maupun penyuluhan kesehatan, maka siswi SMK Muhammadiyah Cawas Klaten kurang memilik pengetahuan yang baik tentang SADARI.

Hasil penelitian ini mendukung hasil penelitian Aeni dan Yuhandini (2018) serta Saragih (2019) dimana mayoritas pengetahuan remaja putri tentang SADARI termasuk kategori cukup sebelum diberikan intervensi berupa penyuluhan kesehatan dengan menggunakan media video.

\section{Pengetahuan Remaja Putri Sesudah Diberikan Penyuluhan Kesehatan melalui Media Video tentang SADARI}

Berdasarkan deskripsi data penelitian didapatkan hasil rata-rata (mean) skor posttest sebesar 11,61 dari 15 item pertanyaan yang diajukan. Sedangkan dilihat dari pengkategorian diketahui mayoritas siswi di SMK Muhammadiyah Cawas Klaten mempunyai pengetahuan baik sebanyak 58\% dan pengetahuan siswi yang kurang turun drastis menjadi $7,2 \%$ sedangkan siswi yang berpengetahun cukup sebanyak $34,8 \%$. Hal ini dapat diartikan bahwa setelah diberikan intervensi berupa penyuluhan kesehatan tentang SADARI dengan media video, siswi meningkat pengetahuannya dimana mayoritas siswi berpengetahuan baik. Hal tersebut menunjukan bahwa tindakan intervensi menggunakan penyuluhan kesehatan dengan media video memberikan perubahan pada tingkat pengetahuan siswi yaitu berupa peningkatan skor rata-rata (mean) tingkat pengetahuan yaitu pada saat pre test sebesar 9,39 dan skor rata-rata (mean) pada post test 11,91.

Menurut asumsi peneliti melalui pemanfaatan media video mampu meningkatkan pemahaman siswi khususnya tentang SADARI yang dapat dipraktekkan secara langsung sewaktu melihat video yang sedang diputar. Pemanfaatan media video dalam pembelajaran dapat memberikan pengalaman belajar yang lebih lengkap, jelas, variatif, menarik serta menyenangkan. Media video termasuk dalam media pendidikan elektronik yang mempunyai kelebihan seperti mengikutsertakan banyak panca indera sehingga lebih mudah dipahami, lebih menarik karena adanya suara dan gambar yang bergerak, tatap 
muka, penyajian dapat dikendalikan, jangkauan relatif besar serta dapat diulang-ulang. Media video dapat dimanfaatkan untuk semua topik dan model-model pembelajaran. Video dapat memperkuat pemahaman responden terhadap materi ajar, merasakan unsur emosi dan penyikapan dari pembelajaran yang efektif serta dapat memberikan kesempatan pada responden untuk mengamati dan mengevaluasi kembali kegiatan tersebut. Dengan demikian mampu meningkatkan pemahaman dan pengetahuan siswi terutama tentang SADARI dan dapat dipraktekkan secara langsung untuk mencegah terjadinya kanker payudara atau sebagai deteksi dini kanker payudara.

Penggunaan media video mempunyai dampak yang lebih pada penyuluhan kesehatan yaitu mengandalkan pendengaran dan penglihatan dari sasaran, menarik, pesan yang disampaikan cepat dan mudah diingat dan dapat mengembangkan pikiran dan mengembangkan imajinasi remaja putri. Penyuluhan kesehatan dengan video pada remaja putri dapat memperjelas gambar-gambar dan langkah-langkah pentingnya pemeriksaan SADARI, karena dalam proses pemberiannya responden tidak hanya mendengar suara tetapi responden akan melihat secara langsung dan jelas langkah-langkah pemeriksaan payudara sendiri (SADARI) (Aeni dan Yuhandiri, 2018).

Hasil penelitian ini mendukung hasil penelitian Rochmaedah (2018); Ulfa dan Azrida (2018) dimana masing-masing hasil penelitian mereka memberikan bukti empiris bahwa mayoritas pengetahuan remaja putri meningkat menjadi baik setelah diberikan intervensi berupa pendidikan kesehatan melalui media video tentang SADARI.

\section{Efektifitas Penyuluhan Kesehatan tentang SADARI dengan media Video terhadap Pengetahuan Remaja Putri tentang SADARI}

Hasil analisis bivariat menggunakan uji wilcoxon signed rank test diperoleh nilai $z$ score sebesar 6,798 dengan signifikansi sebesar 0,000 $<0,05$. Hal ini dapat diartikan bahwa terdapat perbedaan pengetahuan remaja putri antara sebelum dan sesudah diberikan penyuluhan kesehatan tentang SADARI melalui media video, dengan nilai rata-rata (mean) pengetahuan sebelum diberikan penyuluhan kesehatan sebesar 9,39 dan sesudah diberikan penyuluhan kesehatan tentang SADARI melalui media video pengetahuan remaja putri mengalami peningkatan dengan nilai rata-rata sebesar 11,61. Sehingga Ho ditolak dan Ha diterima artinya pemberian penyuluhan kesehatan tentang SADARI melalui media video efektif meningkatkan pengetahuan remaja putri di SMK Muhammadiyah Cawas Klaten.

Menurut peneliti, untuk penyerapan informasi berupa kegiatan yang memerlukan keterampilan dalam ranah psikomotorik, penggunaan media video sangatlah tepat. Karena video dapat menayangkan setiap langkah-langkah kegiatan secara detail sehingga penonton dapat melihat dan menirukan setiap gerakan. Tayangan video dapat diputar berulang kali tanpa merubah isi materi, sehingga siswi dapat memahami betul tentang keterampilan tersebut dan dapat mempraktekkannya. Adanya perubahan sikap siswa dalam menanggapi SADARI menjadi lebih baik bukan hanya dipengaruhi oleh peningkatan pengetahuan. Sikap yang baik juga dapat dipengaruhi oleh pengalaman baik dari keluarga, kerabat maupun teman yang pernah melakukan SADARI serta pengalaman keluarga yang pernah mengalami kanker payudara sehingga muncul motivasi untuk melakukan SADARI. Informasi mengenai SADARI lebih mudah terserap dengan media video karena disertai audio dan visual yang menarik, sehingga praktik-praktik SADARI bisa lebih mudah dilihat karena dapat menampilkan setiap gerakan atau langkah-langkah SADARI, lebih jelas dan kegiatan lebih terarah. Jadi, penyuluhan kesehatan dengan video efektif dalam meningkatkan pengetahuan remja putri dimana seorang remaja dapat menerima pesan dengan cepat dan mudah diingat dapat diterima dengan baik, lebih menarik dan tidak menonton karena remaja mendengar dan melihat sehingga remaja sangat antusias terhadap 
isi video dan melihat video sampai selesai, melalui video remaja akan dipaparkan secara jelas tentang SADARI yaitu pengertian, tujuan waktu dan langkah- langkah SADARI.

Hasil penelitian ini sejalan dengan penelitian yang dilakukan Alini dan Indrawati (2018); Ulfa dan Azrida (2018) dimana penyuluhan kesehatan dengan menggunakan media video tentang SADARI mampu efektif meningkatkan pengetahuan siswi.

\section{KESIMPULAN}

1. Pengetahuan remaja putri sebelum dilakukan penyuluhan kesehatan dengan media video tentang SADARI di SMK Muhammadiyah Cawas Klaten diketahui mayoritas termasuk cukup $(47,8 \%)$.

2. Pengetahuan remaja putri sesudah dilakukan penyuluhan kesehatan dengan media video tentang SADARI di SMK Muhammadiyah Cawas Klaten diketahui mayoritas termasuk baik (58\%).

3. Pemberian penyuluhan kesehatan tentang SADARI melalui media video efektif meningkatkan pengetahuan remaja putri di SMK Muhammadiyah Cawas Klaten (sig = $0,000<0,05)$.

\section{SARAN}

1. Diharapkan pihak sekolah dapat bekerjasama dengan pihak Puskesmas setempat dan atau Fakultas Kesehatan Masyarakat Universitas Veteran Bangun Nusantara Sukoharjo untuk melakukan penyuluhan kesehatan secara aktif dan efektif khususnya terkait reproduksi.

2. Diharapkan pihak sekolah dapat membangun UKS yang mana didalamnya dapat didirikan layanan konseling kepada remaja yang bermasalah terhadap personal care khususnya deteksi dini terhadap kanker payudara melalui pemeriksaan SADARI.

3. Diharapkan pihak sekolah dapat menambah media dalam pembelajaran yang lebih efektif seperti phantom agar proses pembelajaran dan penyampaian pesan serta isi pembelajaran menjadi lebih efektif karena dapat meningkatkan pemahaman siswa, menarik dan memadatkan informasi.

4. Diharapkan Dinas Kesehatan Kabupaten Klaten yang bekerjasama dengan Puskesmas setempat dapat lebih aktif dan efektif melakukan sosialisasi dan penyuluhan pentingnya melakukan deteksi dini terhadap kanker payudara melalui pemeriksaan SADARI khususnya bagi para remaja putri baik melalui media video, leaflet, maupun pendidikan kesehatan lainnya.

\section{DAFTAR PUSTAKA}

Aeni, Nurul dan Diyah Sri Yuhandini. 2018. Pengaruh Pendidikan Kesehatan Dengan Media Video Dan Metode Demonstrasi Terhadap Pengetahuan SADARI. Jurnal Care Vol .6, No.2,Tahun 2018: 162-174.

Alini dan Indrawati. 2018. Efektifitas Promosi Kesehatan Melalui Audio Visual Dan Leaflet Tentang SADARI (Pemeriksaan Payudara Sendiri) Terhadap Peningkatan Pengetahuan Remaja Putri Tentang SADARI di SMAN 1 Kampar Tahun 2018. Jurnal Ners Research \& Learning in Nursing Science Volume 2 Nomor 2 Tahun $2018: 1-9$.

Henny, 2012. Mengenal Seluk Beluk Kanker. Yogyakarta : Katahati

Kemenkes RI Propinsi Jawa Tengah. 2018. Profil Kesehatan Propinsi Jawa Tengah 2018. Semarang: Kemenkes RI. 
Lubis, L, U. 2017. Pengetahuan Remaja Putri tentang Pemeriksaan Payudara Sendiri (SADARI) dengan Perilaku SADARI. (Online). (http://ejournal.stikesaisyiyah.ac.id/index.php/eja, diakses 10 April 2019)

Manuaba, Ida Bagus Gde, Ida Ayu Chandranita Manuaba, dan Ida Bagus Gde Fajar Manuaba. 2015. Ilmu Kebidanan, Penyakit Kandungan, dan KB Untuk Pendidikan Bidan. Ed.2. Jakarta : EGC.

Notoatmodjo, S. 2015. Metode Penelitian Kesehatan. Jakarta: Rineka Cipta

Olfah, Yustiana. 2013. Kanker Payudara dan SADARI. Yogyakarta: Nuha Medika

Rochmaedah, Siti. 2018. Efektivitas Health Education Tentang Sadari Dengan Media Audio Visual Terhadap Tingkat Pengetahuan Siswi MAN Seram Bagian Barat. Global Health Science, Volume 3 No. 4, Desember 2018: 329-333.

Saragih, Erita. 2019. Pengaruh Pendidikan Kesehatan Tentang Sadari Sebagai Deteksi Dini Kanker Payudara Terhadap Pengetahuan Dan Sikap Siswi Di Smk Swasta Arjuna Laguboti Kabupaten Tobasa Tahun 2018. Variasi : Majalah Ilmiah Universitas Almuslim, Volume 11, Nomor 1, Juni 2019: 67 - 72.

Siburian, U.D. 2015. Pengaruh Media Leaflet dan Media Video Terhadap Pengetahuan dan Sikap Mahasiswa Dalam Upaya Deteksi Dini Kanker Payudara di Akademi Keperawatan Pemerintah Kabupaten Tapanuli Selatan. Tesis. Program Studi S2 Ilmu Kesehatan Masyarakat Fakultas Kesehatan Masyarakat Universitas Sumatera Utara Medan.

Ulfa, Siti Mutia dan Rinna Azrida. 2018. Efektivitas Penyuluhan Pemeriksaan Payudara Sendiri (Sadari) Dengan Metode Ceramah Dan Video Terhadap Tingkat Pengetahuan Tentang Deteksi Dini Kanker Payudara Pada Remaja Putri Di SMA Muhammadiyah 01 Medan Tahun 2016. Unit Penelitian dan Pengabdian Masyarakat Fakultas Kedokteran Universitas Muhammadiyah Sumatera Utara. Ibnu Sina Biomedika Volume 2, No. 2 (2018): 144-151.

World Health Organization. 2018. Adolescent Health. [Online]. (http://www.who.int/topics/adolescent_health/en/ index.html diakses tanggal 10 April 2019).

World Health Organization. 2018. Data Global Cancer Observatory 2018. [Online] (http://www.databoks.com/ diakses 5 Februari 2020). 